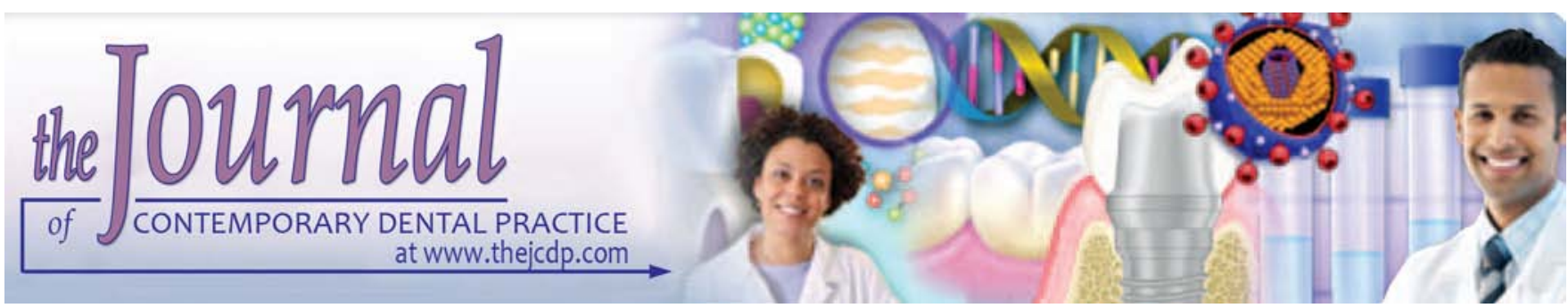

\title{
Use of Three-dimensional Plates in Mid-face Fracture: A Prospective Study
}

\author{
${ }^{1}$ Manpreet Singh, ${ }^{2}$ Amiya Agrawal, ${ }^{3}$ Manoj Chaudhary, ${ }^{4}$ Gagandeep Kaur, ${ }^{5}$ Bhupendra Harjani, ${ }^{6}$ Arvind Yadav
}

\begin{abstract}
Aim: The aim of our study was to evaluate the advantages and disadvantages of three-dimensional (3D) plating system in the treatment of mid-face fractures.

Patients and methods: Thirty mid-face fractures in 18 patients at various anatomic locations were treated by open reduction and internal fixation using 3D plates. All patients were followed at regular intervals of 4 th, 8 th and 12 th weeks respectively. Patients were assessed postoperatively for postoperative complication and occlusal stability. The incidence of neurosensory deficit, infection, masticatory difficulty, nonunion and malunion was also assessed.
\end{abstract}

Results: A significant reduction in fracture $(72.2 \%)$ and occlusal stability $(72.2 \%)$ was seen. The overall complication rate was $(16.6 \%)$ which included two patients who developed postoperative paresthesia of lip, three patients had infection and two cases of masticatory difficulty which later subsided by higher antibiotics and 4 weeks of MMF. No evidence of nonunion and malunion was noted.

Conclusion: Single 3D titanium plates with $1.7 \mathrm{~mm}$ diameter holes and $1.7 \mathrm{~mm}$ screws were reliable and an effective treatment modality for mid-face fracture.

1,3Department of Oral and Maxillofacial Surgery, Kothiwal Dental College and Research Centre, Moradabad, Uttar Pradesh, India

${ }^{2}$ Department of Oral and Maxillofacial Surgery, Career Post Graduate Institute of Dental Sciences and Hospital, Lucknow Uttar Pradesh, India

${ }^{4}$ Department of Conservative Dentistry and Endodontics Kothiwal Dental College and Research Centre, Moradabad Uttar Pradesh, India

${ }^{5}$ Department of Oral and Maxillofacial Surgery, KD Dental College, Mathura, Uttar Pradesh, India

${ }^{6}$ Department of Dentistry, Government Medical College, Banda Uttar Pradesh, India

Corresponding Author: Amiya Agrawal, Reader, Department of Oral and Maxillofacial Surgery, Career Post Graduate Institute of Dental Sciences and Hospital, Lucknow, Uttar Pradesh, India, e-mail: amikgmc@gmail.com
Clinical significance: Because of unique biogeometrical design owing to lesser amount of hardware material (fixation device) resulting into increased stability, the fixation in mid-face fractures is better in comparison to conventional $1.5 \mathrm{~mm}$ miniplate fixation.

Keywords: 3D titanium plates, Mid-face fractures, Open reduction and internal fixation.

How to cite this article: Singh M, Agrawal A, Chaudhary M, Kaur G, Harjani B, Yadav A. Use of Three-dimensional Plates in Mid-face Fracture: A Prospective Study. J Contemp Dent Pract 2015;16(7):571-577.

Source of support: Nil

Conflict of interest: None

\section{INTRODUCTION}

Maxillofacial trauma can have various etiologies, such as road traffic accidents, falls, fight and assaults, sports and others, in isolation or in combination with other injuries. ${ }^{1,2}$ Management of these mid-facial fractures is a challenge for oral and maxillofacial surgeons, demanding a high level of expertise..$^{2-4}$ Maxillofacial fractures are primarily treated to restore the function and esthetics according to the site and severity of the fractures in consideration of other injuries and the general condition of the patient. However, there are anatomical and functional differences between the mid-face and the mandible that greatly affect the consequence of the injuries.

Numerous biomechanical studies illustrate the stability of the rigid fixation for mandibular fractures. ${ }^{4-6}$ However, little research has focused on the maxilla, despite the fact that LeFort fractures and osteotomies are common clinical presentations. For the treatment of LeFort maxillary fractures, the primary aims include the restoration of correct mid-facial vertical height and anterior projection and restoration of occlusion. Nonetheless, the removal rate of the miniplates and screws were approximately $50 \%$ in orthognathic surgery (LeFort I osteotomy), predominantly due to infection or wound 
dehiscence. ${ }^{7}$ The other problem is that patients sometimes complain of weak clenching after the operation, therefore, questions regarding minimum number of plates and stability following fixation have risen in recent times.

Miniplate osteosynthesis, developed by Champy in $1975,{ }^{8}$ is today's standard for the treatment of facial fracture. More recently, resorbable plates ${ }^{2}$ and screws and three-dimensional (3D) miniplating system, ${ }^{3}$ have been introduced for fixation of facial fractures. Many studies have proved the efficacy of 3D plating systems in mandible fractures but very little research have been carried out on mid-face fractures. ${ }^{9,10}$ We studied the efficacy of 3D plates in midface fractures and found them efficacious enough to stabilize the bone fragments during osteosynthesis.

Three dimensional miniplating system was introduced by Farmand. ${ }^{11}$ The basic concept of $3 \mathrm{D}$ fixation is that a geometrically closed quadrangular plate secured with bone screws creates stability in $3 \mathrm{D}$. The $3 \mathrm{D}$ plates are positioned perpendicular to the fracture line. The screws adapt each part of the plate separately without any tension to the bone. The cross-linking provides the stability to the system. Three dimensional miniplates are easy to adjust, requires minimal tissue dissection thus least disturbing the blood supply and because of its design fixation points remain in the vicinity of fracture line. Its low profile design and space between plate holes permits excellent revascularization.

The biomechanical and technical advantages of 3D miniplate systems over 2D miniplate system promoted the current study to evaluate the efficacy of the 3D titanium miniplates as a viable treatment modality in the osteosynthesis of middle-third facial fractures.

\section{MATERIALS AND METHODS}

\section{Study Design}

A total of 30 patients of maxillofacial injuries included for the present study. The patients were recruited from the outpatients department (OPD) and emergency services of Department of Oral and Maxillofacial Surgery, Kothiwal Dental College and Research Centre, Moradabad, Uttar Pradesh, India and were properly screened for inclusion in the present study. Patients with major systemic diseases, e.g. cardiovascular, neurological injuries, etc. any infection at fracture site, pathologic fractures, comminuted fractures, and fractures with extensive bone loss and with history of hypersensitivity reaction to bioresorbable material were excluded in present study.

The study patients comprised with isolated LeFort I fracture, 20 patients had bilateral fracture and 10 patients had unilateral LeFort I fracture. All patients were taken up randomly irrespective of age, sex, caste and creed.

Patients were diagnosed on the basis of clinical examination and radiographic interpretation. Preoperative evaluation included careful examination of the soft tissues and underlying skeleton. A thorough physical examination was carried out to exclude any other injuries.

All selected patients were informed about the experimental nature of the study and the possible complications were explained. Their cooperation was solicited and informed consent was obtained. The patient received prophylactic antibiotic coverage and analgesics at the time of initial presentation.

The patients selected for this study were thoroughly informed about the advantages and disadvantages of this surgical treatment, and consent form was also taken. The study was also approved by ethical committee as it involved open reduction and internal fixation with standard protocol being followed for all maxillofacial traumas.

\section{Radiological Investigations}

On radiological assessment of the fracture site, nature, associated structures and degree of displacement of fractures were properly assessed using submentovertex view and occipitomental view for mid-face and orthopantomograph (OPG) and PA view for mandible. Computed tomography (CT) scan was also done to rule out any neurological injury.

\section{Treatment Planning}

All patients were admitted to the hospital prior surgery. Erich's arch bar were placed on upper and lower standing teeth to stabilize the fracture segment and to achieve occlusion before plating.

\section{Armamentorium required}

- Screwdrivers

- Bone plate holding forceps

- Bone plate bending forceps

- Plate cutting pliers

- Basic instrument set for maxillofacial surgery

- Instrument used for intermaxillary fixation

- Dimensional titanium miniplate: $1.7 \mathrm{~mm}$ system plates Design: Four different designs of 3D titanium miniplates were included:

- $2 \times 2$ holed: Square plate

- $2 \times 2$ holed: Rectangular plates

- $3 \times 2$ holed: Continuous rectangle or double rectangle

- $4 \times 2$ holed: Continuous rectangle plate All the plates had $1.7 \mathrm{~mm}$ diameter holes. 
Screws: Noncompression, self-tapping, monocortical screws with round head.

- Diameter: $1.7 \mathrm{~mm}$

- Length: 5, 7 and $9 \mathrm{~mm}$ Drill Bit

- Diameter: $1.2 \mathrm{~mm}$ Conventional titanium miniplate: $1.7 \mathrm{~mm}$ system

- $1 \times 2$ holed - straight plate Profile height: $1.0 \mathrm{~mm}$

Screws: Noncompression, self-tapping, monocortical screws with round head.

- Diameter: $1.7 \mathrm{~mm}$

- Length: 5, 7 and $9 \mathrm{~mm}$

Drill Bit: Diameter-1.2 mm

\section{Operative Procedure}

Surgical management of all patients included in this study was open reduction and internal fixation with $3 \mathrm{D}$ plates. All patients were operated under general anesthesia via nasotracheal intubation.

In aforementioned study, the fracture sites were exposed through standard intraoral vestibular incision. (Fig. 1). Operative technique for reduction of maxillofacial injuries by conventional plate was similar to 3D miniplates. Following reduction of the fragments and temporary maxillomandibular fixation was done to achieve preoperative temporary occlusion, a suitable 3D plate was selected and bent with a plate bending pliers to conform the proper adaptation of plates to bone surface.

Intraoral vestibular incision was used in all the patients and after fracture reduction either conventional 2D L-shaped plate was fixed at zygomaticomaxillary buttress region and two holes with gap miniplate was placed over nasomaxillary buttress region.

The 3D titanium miniplates were then positioned in such a way that the horizontal cross-bars were perpendicular to the fracture line and the vertical ones were parallel to it (Fig. 2). Holding the plate perpendicular to

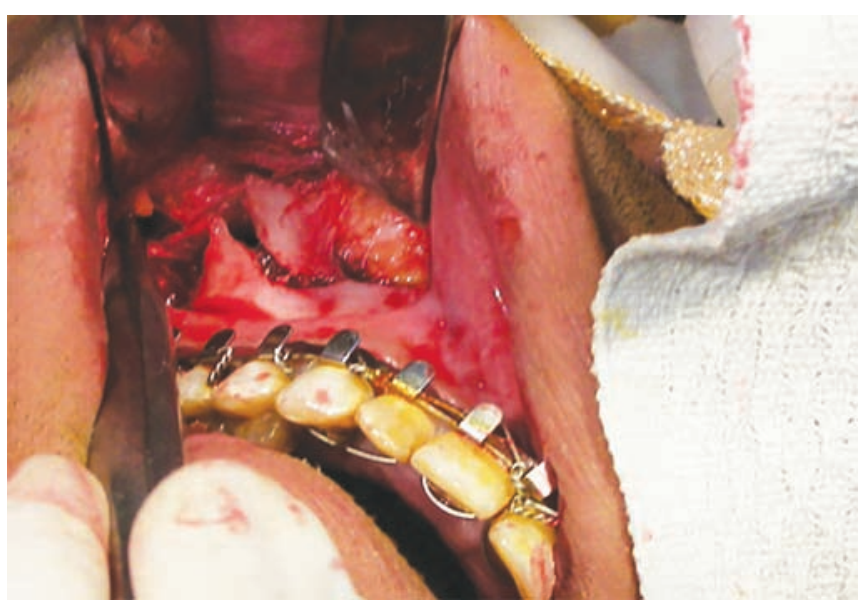

Fig. 1: Exposure of fracture site the reduced fracture, drilling was performed through the hole in the plate strictly perpendicular to the bone surface. The drilling was performed at slow-speed along with copious saline irrigation to prevent damage to the bone by heat. To avoid injury to the dental roots the superior holes were drilled strictly monocortical, and directed into the space between the roots.

Later screws of suitable length were selected for fixation of the plate. In each case, the upper screws were tightened first, followed by the lower ones. For screw tightening the rotations were executed using the screwholding screw driver.

Maxillomandibular fixation was released and occlusion was checked by moving the lower jaw. The site was closed using 3-0 silk suture material. No maxillomandibular fixation was required in any of the patient.

\section{Postoperative Management}

Postoperative course of medication consisted of injection Ceftriaxone $1 \mathrm{gm} 12$ hourly intravenously, injection Metrogyl $100 \mathrm{ml} 8$ hourly intravenously and analgesic and multivitamin preparation continued till 5 th postoperative day. All patients were put on liquid diet for first 2 weeks. All patients were encouraged to maintained good oral hygiene. Sutures were removed on the 7 th postoperative day. All patients were followed-up at regular interval that is at 1st week, 3rd week, 6th week and 3 months postoperatively regarding restoration of function, stability of system used and any complication.

Assessment of the patients was done for following parameters:

- Pain: Visual analog scale (VAS) (0-10)

- Swelling: Present/absent

- Occlusion: Deranged/intact

- Mobility of fracture segment: Present/absent

- Infection/wound dehiscence: Present/absent

- Parasthesia: Present/absent

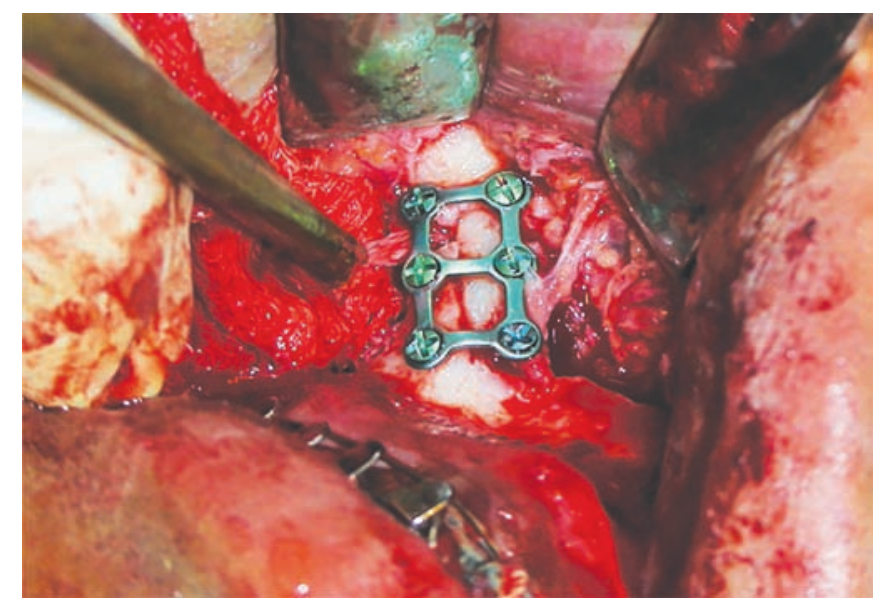

Fig. 2: Fracture reduction and plate fixation 


\section{STATISTICAL ANALYSIS}

Continuous data were summarized as mean \pm SD while discrete (categorical) in no. and percentage. Continuous groups were compared by repeated measures one way analysis of variance (ANOVA) and the significance of mean difference between the groups was done by Tukey's post hoc test. Categorical groups were compared by Chisquare $\left(\chi^{2}\right)$ test. A two-tailed $(\alpha=2)$ p-value less than 0.05 $(p<0.05)$ was considered statistically significant.

\section{RESULTS}

The postoperative outcome measures of patients over the periods are summarized in Table 1 and also shown in Graphs 1 to 6, respectively. The treatment induced significant $(\mathrm{p}<0.001)$ improvement $(84.0 \%)$ in pain at final evaluation ( 3 month) as compared to 1 week. Further, at final evaluation, the swelling $(100.0 \%)$, occlusion $(90.0 \%)$, mobility of fracture segment (100.0\%), infection/ wound dehiscence $(100.0 \%)$ and para thesis $(96.7 \%)$ also improved significantly $(\mathrm{p}<0.05$ or $\mathrm{p}<0.01$ or $\mathrm{p}<0.001)$.

\section{DISCUSSION}

LeFort I maxillary fractures are among the injuries encountered most frequently in patients who suffer facial trauma and it is common in orthognathic surgery. Fixation of maxillary LeFort I fractures or Osteotomy procedures done in orthognathic surgeries by open reduction internal fixation of the facial skeleton has become an accepted, and even expected, form of treatment. When the teeth of the maxilla and mandible are clenched, anatomic support for the mid-face is provided through a series of buttresses or struts that distribute masticatory forces from the teeth to skull base. ${ }^{10,11}$ The vertical struts of the midface are clinically the most important in management of LeFort I maxillary fractures. The three principal vertical buttresses of the maxilla are the nasomaxillary (medial) buttress, zygomaticomaxillary (lateral) buttress, and the pterygomaxillary (posterior) buttress. ${ }^{4,12}$ The internal fixation of LeFort I fractures should use miniplates and screws and be fixed at anterior and lateral buttresses for the ideal internal fixation, whereas the posterior buttress should be without fixation due to the surgical difficulty of the operative approach. ${ }^{4,13}$ Surgical treatment of LeFort I fracture according to the 'ideal internal fixation' produces satisfactory results, but patients sometimes complain of weak clenching after the operation. Very few comparisons of the different maxilla fixation modalities and their behavior have been reported currently. In clinical LeFort I fracture treatment, restoration of the correct midfacial vertical height and anterior projection and restoration of occlusion are critical.

Therefore, questions have arisen regarding the stability and number of plates required of adequate fixation of LeFort fractures.

The fixation of two miniplates on each side as suggested by AO/ASIF, provides adequate stability and conventionally it has been the standard treatment for LeFort fractures.

Farmand in 1992 developed new titanium miniplate system that takes advantage of biogeometry to provide stable fixation and he called it as $3 \mathrm{D}$ plating systems. ${ }^{14} \mathrm{~A}$ geometrically closed quadrangular plates secured with bone screws creates stability in 3D. These plates have low profile design, excellent biocompatibility, and minimal rebound after bending. ${ }^{15}$

The present study was carried on patient's age group 10 to 50 years with the mean being 33.14 years. The maximum numbers of patients were in an age group between 31 and 50 years (nearly 50\%). This is in accordance with the study of Khateeb and Abdullah FM. ${ }^{17}$

There was predominance of males in this study, male is to female ratio being 13:1, and percentage of male patients being $92 \%$. Motamedi $\mathrm{MH}^{2}$ observed in a retrospective study on 237 patients, percentage of male patients being $89 \%$ and that of female patients being $11 \%$, our study is in accordance with this study.

In this study, road traffic accident $(92 \%)$ were found to be the major etiological factor for the fracture of the middle third of the facial skeleton. These findings coincides with the findings of, Iida S et al and Agrawal A et al who reported road traffic accident to be the most common

Table 1: Postoperative distribution of outcome measures of patients over the periods

\begin{tabular}{lllllll}
\hline & \multicolumn{9}{c}{ Periods } & \\
\cline { 2 - 5 } Outcome measures & $\begin{array}{l}\text { 1st week }(n=30) \\
(\%)\end{array}$ & $\begin{array}{l}\text { Srd week }(n=30) \\
(\%)\end{array}$ & $\begin{array}{l}\text { 6th week }(n=30) \\
(\%)\end{array}$ & $\begin{array}{l}\text { 3 months } \\
(n=30)(\%)\end{array}$ & F/ $\chi^{2}$ value & $p$-value \\
\hline Pain (VAS): Mean \pm SD & $5.17 \pm 1.37$ & $3.57 \pm 1.19$ & $2.10 \pm 1.21$ & $0.83 \pm 0.70$ & 79.86 & $<0.001$ \\
Swelling: present & $15(50.0)$ & $3(10.0)$ & $1(3.3)$ & $0(0.0)$ & 36.21 & $<0.001$ \\
Occlusion: deranged & $26(86.7)$ & $20(66.7)$ & $12(40.0)$ & $3(10.0)$ & 39.84 & $<0.001$ \\
Mobility: present & $9(30.0)$ & $6(20.0)$ & $2(6.7)$ & $0(0.0)$ & 13.36 & 0.004 \\
Infection: present & $8(26.7)$ & $5(16.7)$ & $3(10.0)$ & $0(0.0)$ & 9.81 & 0.020 \\
Parathesis: present & $9(30.0)$ & $5(16.7)$ & $3(10.0)$ & $1(3.3)$ & 9.15 & 0.027 \\
\hline
\end{tabular}




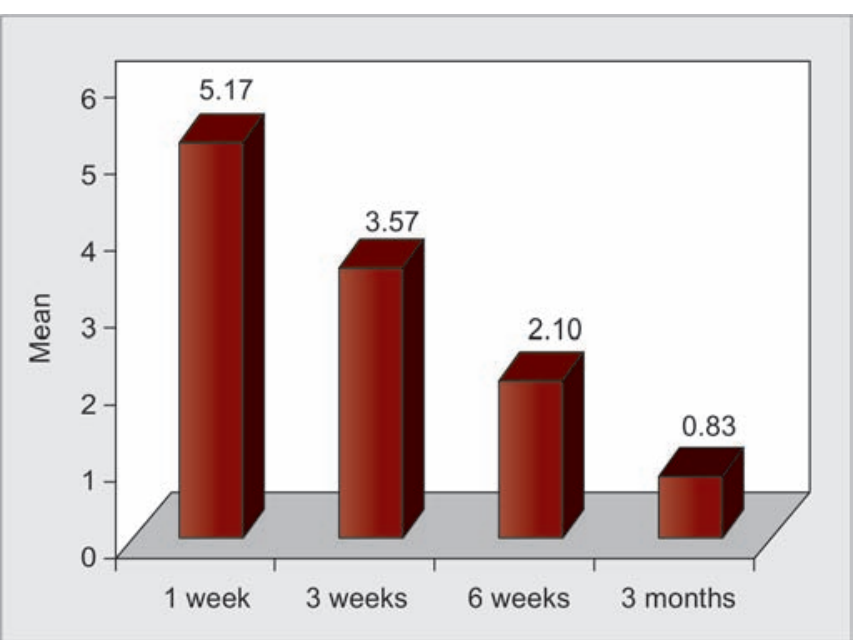

Graph 1: Pain levels (VAS) of treated patients over the periods

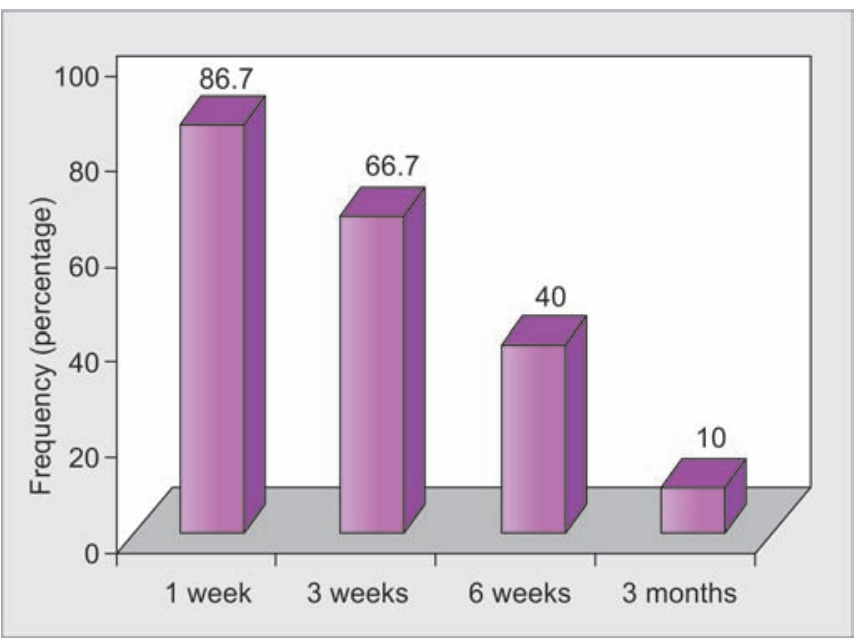

Graph 3: Postoperative frequency distribution of deranged occlusion of patients over the periods

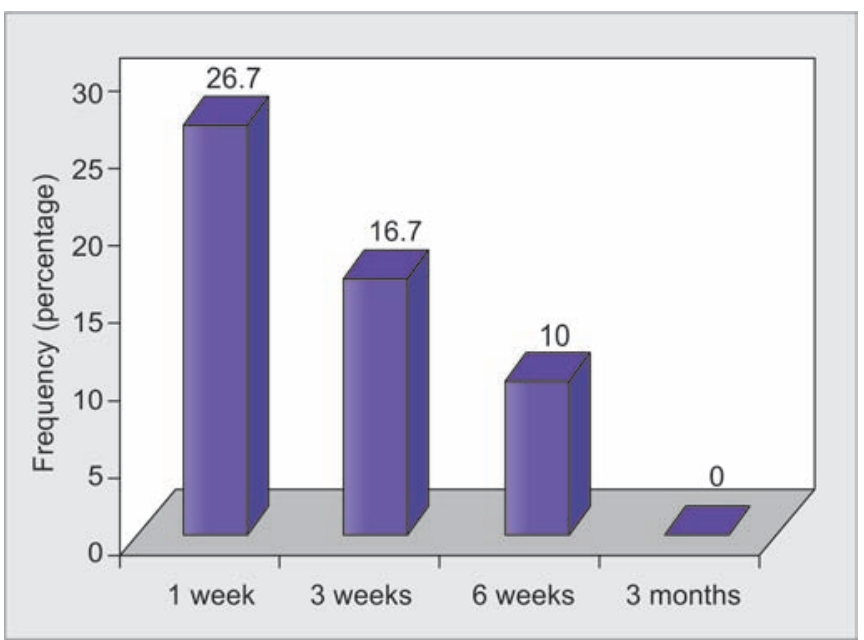

Graph 5: Postoperative frequency distribution of infection/ wound dehiscence of patients over the periods

cause of injury in a retrospective analysis of 1,502 patients and 1,088 patients with facial fractures respectively. ${ }^{1,24}$

In the present study, it was observed that among the maxillary fractures, LeFort II fractures (approx 78\%) were

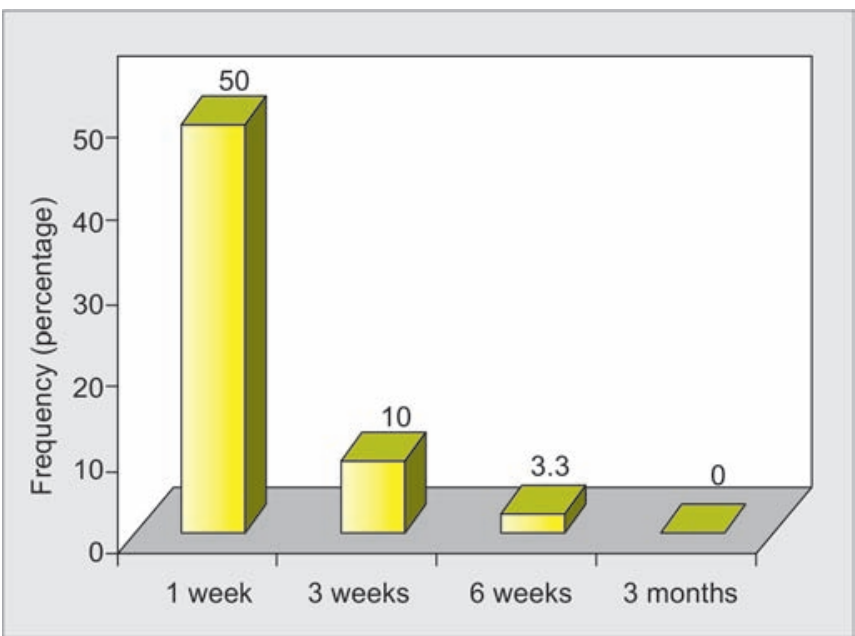

Graph 2: Postoperative frequency distribution of swelling of patients over the periods

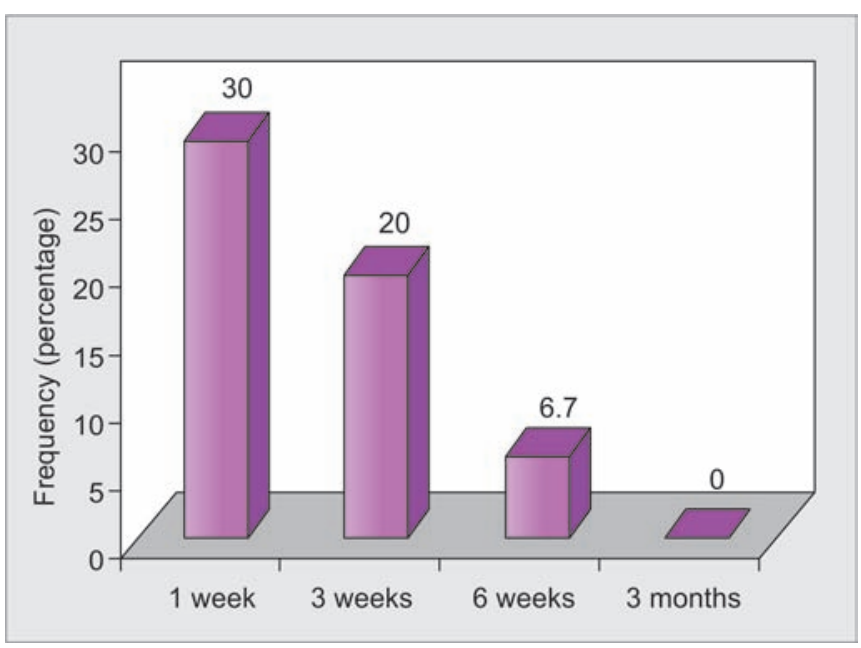

Graph 4: Postoperative frequency distribution of mobility of fracture segment of patients over the periods

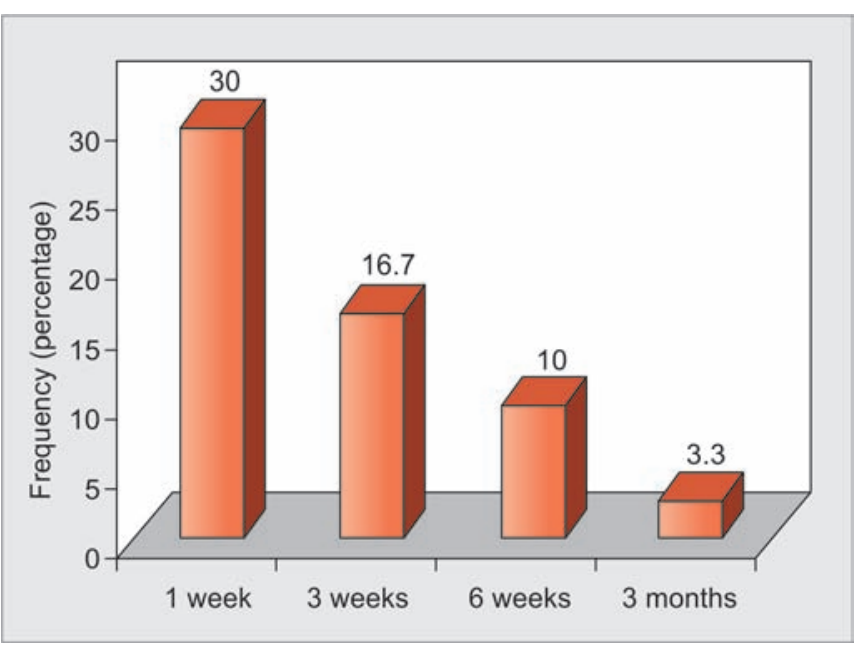

Graph 6: Postoperative frequency distribution of parathesis of patients over the periods

most common, this finding is in accordance with the study Motamedi MH which reported the incidence of LeFort II fractures to be $54.6 \%$ among all maxillary fractures in a 5-year retrospective study on 237 patients. $^{2}$ 
In the present study, post traumatic parasthesia of the infraorbital nerve was present in four cases (57.14\%) (out of the seven patients with zygomatic complex fractures) which was clinically inferred as compression of nerve by fracture fragments. Anesthesia was relieved in three $(75 \%)$ out of four patients in a 3-month follow-up period which found to be due to infraorbital nerve relieved from compression by means of reduction of fractured segments in to its correct position. De Man K et al reported the presence of sensory disturbances of infraorbital nerve in 219 cases $(80.2 \%)$ out of 273 patients. ${ }^{12}$

The influence of treatment approach on the recovery of the injured infraorbital nerve is controversial in the literature. Several authors reported that frequency of persistent sensory disturbance is independent of the method of reduction and fixation of fracture. De Man K et al stated that reduction and fixation are important factors in recovery from sensory disturbances of infraorbital nerve. ${ }^{12}$ Taicher observed that there is higher recovery rate of infraorbital nerve with miniplate osteosynthesis than with other method of treatment. ${ }^{18}$ We report a (75\%) recovery rate of in our study and our results support these findings. This significantly high recovery rate with $3 \mathrm{D}$ plate can be explained by the fact that fixation with $3 \mathrm{D}$ plate provides better stability to the complex in all the 3D of movement. However, there is no study in the literature on the recovery of infraorbital nerve after fixation with $3 \mathrm{D}$ plates.

In the present study, occlusion was achieved in all the patients after surgery. Conventional treatment with maxillomandibular fixation is associated with its well known limitations and disadvantages. Klotch DW studied internal fixation vs conventional therapy in midface fractures and found that a more stable occlusion is achieved with internal fixation. ${ }^{19}$ Anand SS et al studied the use of 3D plate fixations of fractures and osteotomies and stated that satisfactory occlusion was achieved in all the patients after internal fixation with 3D plates and no patient required any maxillomandibular fixation. ${ }^{20}$ Claude Guimond studied the use of 3D plate for fixation of mandibular factures and reported similar findings in their study. ${ }^{21}$ As 3D plates provide stability in three dimensions of movement the need for maxillomandibular fixation is greatly diminished or moreover eliminated. Our study is in accordance with these studies.

No patient reported for any type of postoperative infection, wound dehiscence during the period of 3-month follow-up. Lai G reported the similar results in his study. He found no postoperative complications in 30 treated cases of 3D titanium bone plating. ${ }^{22}$ Anand SS studied the role of 3D plating system and did not reported any infection in their study. ${ }^{20}$ Claude Guimond studied the use of 3D plating in mandibular fractures and reported a significantly low rate of infection as compared with other systems. ${ }^{21}$ Farmand studied the use of 3D plates in fixation of fracture and osteotomies and reported a significantly low rate of postoperative infection with 3D plates. ${ }^{23}$ No infection in our cases could be attributed to the preoperative antibiotic therapy in all patients, and proper sterilization technique.

In none of the patients plates need to be removed exhibiting there excellent biocompatibility in this short period of study. Farmand in their respective studies on the use of 3D plates in oral and maxillofacial region did not report any hardware failure with the use of these plates, ${ }^{11}$ our study is in accordance with these studies.

\section{CONCLUSION}

Thus, as a result of clinical experience, it can be inferred that the use of $3 \mathrm{D}$ plates and screw system in the management of midfacial fractures gives good results in term of function, esthetic and acceptability.

\section{REFERENCES}

1. Iida S, Kogo M, Sugiura T, Mima T, Matsuya T. Retrospective analysis of 1502 patients with facial fractures. Int J Oral Maxillofac Surg 2001;30:286-290.

2. Motamedi MH. An assessment of maxillofacial fractures: a 5-year study of 237 patients. J Oral Maxillofac Surg 2003;61: 61-64.

3. Erdmann D, Follmar KE, DeBruijn M, Bruno AD, Jung SH, Edelman D, Mukundan S, Marcus JR. A retrospective analysis of facial fracture etiologies. Ann Plast Surg 2008;60:398-403.

4. Van den Bergh B, Karagozoglu KH, Heymans MW, Forouzanfar T. Aetiology and incidence of maxillofacial trauma in Amsterdam: a retrospective analysis of 579 patients. J Craniomaxillofac Surg 2012;40:e165-e169.

5. Al Ahmed HE, Jaber MA, Abu Fanas SH, Karas M. The pattern of maxillofacial fractures in Sharjah, United Arab Emirates: a review of 230 cases. Oral Surg Oral Med Oral Pathol Oral Radiol Endod 2004;98:166-170.

6. Erol B, Tanrikulu R, Görgün B. Maxillofacial fractures. Analysis of demographic distribution and treatment in 2901 patients (25 year experience) J Craniomaxillofac Surg 2004;32:308-313.

7. Brasileiro BF, Passeri LA. Epidemiological analysis of maxillofacial fractures in Brazil: a 5 year prospective study. Oral Surg Oral Med Oral Pathol Oral Radiol Endod 2006;102:28-34.

8. Champy M, Loddé JP, Schmitt R, Jaeger JH, Muster D. Mandibular osteosynthesis by miniature screwed plates via a buccal approach. J Maxillofac Surg 1978;6:14-21.

9. Cheema SA, Amin F. Incidence and causes of maxillofacial skeletal injuries at the Mayo Hospital in Lahore, Pakistan. Br J Oral Maxillofac Surg 2006;44:232-234.

10. Bakardjiev A, Pechalova P. Maxillofacial fractures in Southern Bulgaria-a retrospective study of 1706 cases. J Craniomaxillofac Surg 2007;35:147-150.

11. Farmand M, Dupoirieux L. The value of three-dimensional plates in maxillofacial surgery. Rev Stomatol Chir Maxillofac 1992;93:353-357. 
12. De Man K, Bax WA. The influence of the mode of treatment of zygomatic bone fractures on the healing process of the infraorbital nerve. Br J Oral Maxillofac Surg 1988;26:419-425.

13. Lee JH, Cho BK, Park WJ. A 4-year retrospective study of facial fractures on Jeju, Korea. J Craniomaxillofac Surg 2010;38: 192-196.

14. Gandhi S, Ranganathan LK, Solanki M, Mathew GC, Singh I, Bither S. Pattern of maxillofacial fractures at a tertiary hospital in northern India: a 4-year retrospective study of 718 patients. Dent Traumatol 2011;27:257-262.

15. Farmand M. The 3D plating system in maxillofacial surgery. J Oral Maxillofac Surg 1993;51:166-167.

16. Naveen Shankar A, Naveen Shankar V, Hegde N, Sharma Prasad R. The pattern of the maxillofacial fractures: A multicentre retrospective study. J Craniomaxillofac Surg 2012;40:675-679.

17. Al-Khateeb T, Abdullah FM. Cranio maxillofacial injuries in the United Arab Emirates: a retrospective study. J Oral Maxillofac Surg 2007;65:1094-1101.
18. Taicher S, Ardekian L, Samet N, Shoshani Y, Kaffe I. Recovery of the infraorbital nerve after zygomatic complex fractures: a preliminary study of different treatment methods. Int J Oral Maxillofac Surg 1993 Dec;22(6):339-341.

19. KlotchDW, Gilliland R. Internal fixation vs conventional therapy in midface fractures. J Trauma 1987 Oct;27(10):1136-1145.

20. Anand SS, Thangavelu A. Role of indigenous 3-D plating system in oral and maxillo facial surgery. J Maxillofac Oral Surg 2004;3:24-27.

21. Guimond C, Johnson JV, Marchena JM. Fixation of mandibular angle fractures with a $2.0 \mathrm{~mm}$ 3-dimensional curved angle strut plate. J Oral Maxillofac Surg 2005;63:209-214.

22. Lai G. The three-dimensional titanium miniplate rigid fixation in the treatment of fracture of maxilla. Zhongguo Xiu Fu Chong Jian Wai Ke Za Zhi 1997;11:196-198.

23. Farmand $M$. Three dimensional plate fixation of fractures and osteotomies: Facial plastic surgery. Clin North Am 1995;3:39-56.

24. Agrawal A, et al. Maxillofacial fracture patterns in north Indian urban population. J Dent Sci Res 2013;4(1):1-4. 